\title{
Counting One's Blessings Can Reduce the Impact of Daily Stress
}

\author{
Izabela Krejtz • John B. Nezlek • Anna Michnicka • Paweł Holas • \\ Marzena Rusanowska
}

Published online: 30 September 2014

(C) The Author(s) 2014. This article is published with open access at Springerlink.com

\begin{abstract}
Participants in the present study, adults living in the community, described their well-being and the stress they experienced each day for 2 weeks. Before completing these diaries each day, half of the participants described the things for which they felt grateful that day, and half completed the diaries without doing this. Multilevel modeling analyses found that daily feelings of gratitude were positively related to well-being at the within-person level, and lagged analyses suggested a causal link from well-being to gratitude. In addition, relationships between daily stress and daily well-being were weaker for people who had been asked to think about the things for which they were grateful than they were for those who had not been asked. These results suggest that counting one's blessing can reduce the negative effects of daily stress, which in turn may have positive long-term effects on mental health.
\end{abstract}

Keywords Gratitude $\cdot$ Diary study $\cdot$ Well-being $\cdot$ Multilevel modeling

I. Krejtz · A. Michnicka

University of Social Sciences and Humanities, Warsaw, Poland

J. B. Nezlek

University of Social Sciences and Humanities, Poznań, Poland

J. B. Nezlek (ه)

Department of Psychology, College of William \& Mary, PO Box 8795, Williamsburg, VA 23185, USA

e-mail: jbnezl@wm.edu

P. Holas

Warsaw Medical University, Warsaw, Poland

M. Rusanowska

Jagiellonian University, Kraków, Poland 


\section{Introduction}

Gratitude is broadly defined as the state of being grateful for various gifts in life such as the presence of cherished others in one's life (e.g., Lambert et al. 2009) and as the recognition and appreciation of altruistic gifts (Emmons 2004). Moreover, a growing body of research suggests that gratitude is associated with positive outcomes (Wood et al. 2010). Much of this research has examined gratitude as a disposition, a trait-like characteristic that is assumed to be relatively stable across time. People are assumed to be more or less grateful, just as they are assumed to vary on openness, agreeableness, and other individual differences.

Although it is certainly reasonable to treat gratitude as a disposition, similar to other individual differences, we believe that gratitude also has an important state component (e.g., Roberts 2004). People can feel more or less grateful across time and circumstances, and the present study examined such variability. For 2 weeks, participants maintained a diary. At the end of each day, they described how grateful they felt that day, the events that happened, and they provided various measures of well-being. In addition, before providing this information each day, half the participants described the things for which they felt grateful and half did not. We describe our expectations for the results after a brief review of the relevant literature.

\subsection{Correlates of Gratitude}

The existing research indicates that feeling grateful has broad positive effects on people. These effects include, but are not limited to, increased subjective well-being (Watkins 2004; McCullough et al. 2004), lowered negative states such as depression, social anxiety (Kashdan and Breen 2007), and lowered stress (Krause 2006). The positive effects of gratitude also include physical well-being such as improved sleep quality (Emmons and McCullough 2003; Digdon and Koble 2011). For example, grateful thoughts before falling asleep were associated with higher subjective quality of sleep and with better functioning the following day (Wood et al. 2009b). Similarly, research suggests that feelings of gratitude are associated with other positive outcomes such as emotional and social functioning (Wood et al. 2010). These include positive emotions, warmth, altruism, gregariousness, and trust (Wood et al. 2008, 2009a).

Feeling grateful also leads to better interpersonal relationships, including greater satisfaction from romantic partners (Gordon et al. 2011). One explanation for this effect is that feeling grateful for one's partner motivates one to search for possible solutions to conflicting situations (e.g., Kubacka et al. 2011). More broadly, feelings of gratitude are positively related to a general tendency to behave prosocially (e.g., Bartlett and DeSteno 2006) and to social integration (Froh et al. 2011).

It also appears that gratitude buffers the effects of negative events or experiences. For example, Kashdan, Uswatte, and Julian (2006) found that Vietnam war veterans who reported higher levels of dispositional gratitude were less likely to experience PTSD compared to veterans with lower levels of dispositional gratitude. Moreover, regardless of PTSD status, at the within-person level, daily gratitude was positively related to measures of well-being such as daily self-esteem and positive affect. Ruini and Vescovelli (2013) studied women with breast cancer. Individual differences in dispositional gratitude were positively related to post-traumatic growth and positive emotions and were negatively related to distress. Interestingly, gratitude was not related to psychological well-being.

It is important to note that relationships between gratitude and various positive states reflect the effects of gratitude per se. For example, although gratitude is related to positive 
feelings, it is distinct from happiness (Emmons and McCullough 2003; Weiner 1985). Gratitude is related to declared religiosity (Emmons and Kneezel 2005), but it is more universal and can exist independent of religious beliefs (Tsang et al. 2012). The interpersonal positive effects of gratitude cannot be explained by reciprocity rules or a sense of indebtedness (Watkins et al. 2006). Gratitude and reciprocity are associated with different emotional states. Gratitude is associated with positive emotions, whereas the feelings of obligation or indebtedness that may result from receiving help are likely to be associated with more negative emotions.

\subsection{Studies of Manipulations of Gratitude}

Although it appears that gratitude is distinct from related constructs, much of the research on gratitude is correlational in nature making it difficult to draw firm conclusions about cause and effect relationships (Wood et al. 2010). To examine causal relationships between gratitude and other constructs, in some studies, gratitude has been manipulated. Wood et al. (2010) classified such studies into three categories: (a) daily listing of things for which to be grateful, (b) grateful contemplation, and (c) behavioral expressions of gratitude. The present study used a method similar to what Wood et al. defined as daily listing, and so we focus on some of the studies that have used lists or similar manipulations.

One of the pioneering studies in this domain is Emmons and McCullough (2003). They examined if making people feel more grateful would improve their health and well-being. In three studies, participants either listed their blessings or provided some type of other report such as hassles and daily experiences as a control on a daily or weekly basis. Although the results were not entirely consistent across the three studies, the authors concluded that: "The gratitude-outlook groups exhibited heightened well-being across several, though not all, of the outcome measures across the 3 studies, relative to the comparison groups. The effect on positive affect appeared to be the most robust finding" (p. 377). Interestingly, Emmons and McCullough did not examine within-person relationships for any of their studies. They relied upon measures that were aggregated over time.

More recently, Geraghty et al. (2010) found that maintaining a daily gratitude diary for 2 weeks (listing the things for which they felt grateful) reduced body dissatisfaction. Kerr et al. (2014) examined the efficacy of 2-week gratitude and kindness interventions in a clinical sample waiting for treatment. Participants in the intervention conditions listed the things for which they felt grateful or the acts of kindness they had committed. Both interventions enhanced satisfaction with daily life, optimism, and reduced anxiety compared to a placebo condition, although neither intervention changed overarching constructs such as life satisfaction. Toepfer et al. (2012) examined the effects of writing letters expressing gratitude. As expected, among gratitude writers happiness and life satisfaction increased whereas depressive symptoms decreased.

\subsection{The Present Study}

Although numerous studies have measured gratitude using an intensive repeated measures design (e.g., every day), with the exception of Kashdan et al. (2006), within-person relationships between gratitude and well-being have not been examined. Moreover, studies of gratitude interventions have focused primarily, although not exclusively, on pre and post intervention differences in well-being and global measures of gratitude, which have sometimes been aggregates of repeated measures. It is important to examine within-person relationships between gratitude and other constructs because within- and between-person 
relationships between the same constructs are mathematically independent and may differ (Nezlek 2012), and they may represent meaningfully different psychological processes (e.g., Affleck et al. 1999).

The present study is the first, to our knowledge, that combines measure of daily gratitude and its relation to daily well-being, analyses of the within-person relationships between these measures, and a gratitude intervention. The gratitude manipulation we used was modeled after that used by Emmons and McCullough (2003). Each day, half of the participants described the things for which they felt grateful before they completed their diaries, and half completed their diaries without explicitly describing the things for which they felt grateful. We decided to manipulate gratitude rather than examine naturally occurring differences in dispositional gratitude because this allowed us to control for individual differences that might naturally covary with feelings of gratitude. Such covariates would weaken the strength of our inferences regarding the effects of gratitude if we had studied naturally occurring differences in dispositional gratitude.

Our general expectations were that within-person (day level) relationships between gratitude and well-being would be positive, similar to the relationships that have been found in research that has examined between-person relationships and to the results of Kashdan et al. (2006). In addition, we expected that individuals who described the things for which they felt grateful each day would react less strongly to the stressors in their lives than those who did not. This expectation was based on previous research that has found that gratitude is associated with better coping with distress (e.g., Kashdan et al. 2006; Ruini and Vescovelli 2013).

\section{Method}

\subsection{Participants}

The sample consisted of 58 community members. They were recruited via an open call posted on Facebook and in a local voluntary services center. At an introductory session, participants were told about the study and how to use the website that was used to collect their data. Participants were randomly assigned to one of two groups. The gratitude group $\left(N=29,19 \mathrm{~F}, M_{\text {age }}=27.1, S D=5.76\right)$ and the control group $(N=29,17 \mathrm{~F}$, $\left.M_{\text {age }}=28.81, S D=5.82\right)$ did not significantly differed in age and gender proportion. Most participants had a life partner, (54\% were members of an unmarried couple and $11 \%$ were married), and $35 \%$ were single. Participants were paid approximately 50USD for their help. All participants were native Poles, and all materials were translated and backtranslated from English by individuals fluent in both languages.

\subsection{Daily Measures}

Each day for 2 weeks, participants provided measures of the events that happened each day and measures of well-being. Participants described daily events in terms of one of 10 categories (interpersonal, family, partnership and marriage, health and physical symptoms, hobby, work and duties, moral and values, everyday life, contacts with administration, financial). They rated each event in terms of stressfulness, positivity, importance, and mindfulness using a 7-point response scale anchored with $1=$ not at all and $7=$ very much. In this article, we consider only daily stress, defined as the mean of the stress scores for all the events in a day. 
Our daily measures of well-being and adjustment have been used previously in numerous studies. Each measure was based on a corresponding trait measure of the same construct with items selected for appropriateness for daily administration and reworded. See Nezlek (2012, pp. 141-145) for a discussion of such procedures. All daily items included the word "today" to maximize the likelihood that participants were describing how they felt each day.

Daily gratitude was measured with three items based on the trait level measure introduced by McCullough et al. (2002). How many things were in your life today that you can be grateful for? Today, how much were you able to appreciate people, events, and situations that have been part of your life story? Today, how much time passed before you felt grateful to someone or something?

Daily affect was measured using a circumplex model (based on Feldman et al. 1998), a combination of positive-negative, active-deactive emotions that produced four measures. Following the stem "Today, I felt...", for each item, participants described how they felt using a 7-point scale ranging from 1 ("Did not feel this way at all") to 7 ("Felt this way very strongly"). Positive active affect was measured with ratings of happy, proud, and excited/enthusiastic, and positive deactive affect was measured with ratings of calm, satisfied, and relaxed. Negative active affect was measured with ratings of upset, stressed, and angry, and negative deactive affect was measured with ratings of sad, bored, and disappointed.

Other daily measures included self-esteem, depressogenic adjustment, worry, and complaining all of which were answered using 1-7 scales, scored so that higher numbers indicated higher self-esteem, better adjustment, and more worrying and complaining. Daily self-esteem was measured using three items from Rosenberg (1965). Today, I felt that I was a valuable person, at least as good as others. Today, I felt like a failure (reversed). Daily depressogenic adjustment was measured with three items based on Beck's (1972) triad. Thinking about today in general how positive were your thoughts about yourself? How well did things go today? Today, how optimistic are you about how your life (in general) will be tomorrow?

Daily worry was measured with three items taken from Meyer et al. (1990). How much did your worries overwhelm you today? How much today you were not able to stop worrying once you've started to worry? How much did you worry today? Given the proposed importance of complaining to Polish culture (Wojciszke 2005), we also included three items measuring complaints. Today, how much did you complain? How many reasons to complain did you have today, but you decided not to speak them out? How pleasurable was complaining to you today?

\subsection{Gratitude Manipulation}

In the gratitude condition, at the beginning of each daily data recording session participants were presented with the following instructions, taken from Emmons and McCullough (2003): "There are many things in our lives, both large and small, that we might be grateful about. Think back over the day and write down on the lines below all that you were grateful today." Participants could describe up to 6 things for which they were grateful.

\subsection{Compliance with Instructions}

Before analyzing the data, we inspected the date and time stamps of participants' entries. To be considered valid, an entry needed to have been made after 8:00 pm of the day in 
question or before noon of the following day. Entries that were provided outside of these limits were deleted. Following this procedure, we deleted the data of one participant from the gratitude condition, and the remaining 57 participants provided 781 days of valid data $(M=13.9, S D=3.8)$.

\section{Results}

The data were conceptualized as a two level structure in which days were nested within individuals, and the data were analyzed with a series of multilevel models using the program HLM. The analyses followed the guidelines and procedures described by Nezlek (2012). Before the primary analyses, the reliability of each daily measure was examined with a series of three level models in which items were nested within occasions (days) and occasions were nested within persons (Nezlek 2012). Such analyses provide the multilevel equivalent of a Cronbach's alpha, corrected for differences between persons and days.

These results suggested that the three items we used to measure daily gratitude did not constitute a reliable scale: the estimated reliability was .12. Additional analyses suggested that responses to the third item "Today, how much time did it have to go before you felt grateful to someone or something?" were not closely related to responses to the first two items. Therefore, we defined daily gratitude as the mean response to the first two of the three items we asked. The reliability analyses are summarized in Table 1. Note that no reliability estimate for number of stressful events is presented. As discussed by Stone et al. (1991), reliability analyses are not appropriate for count-based data.

Note also that the reliabilities for our daily measures tend to be lower than reliabilities for comparable single assessment, trait level measures. To avoid overloading participants, diary studies usually ask fewer items for each construct than are asked on trait level measures (e.g., Nezlek 2012). Although this tends to reduce reliability, the multilevel analyses we conducted compensate for this to an extent by using what is called "Bayes shrinkage." The reliability of coefficients for each unit of analysis individual contributes to parameter estimates.

In addition to reporting the statistical significance of fixed effects (the primary focus of our hypotheses and analyses), for significant and marginally significant fixed effects we also report effects sizes in terms of the percent reduction in residual variance estimates. These percents were calculated by subtracting the residual variance from an analysis with predictors from the residual variance from the null model (no predictors). These estimates were calculated separately for level 1 and level 2 models. Although there is some disagreement about the use of such variance estimates within the multilevel context (e.g., Kreft and de Leeuw 1998), we thought that including them would help readers understand the results more fully.

\subsection{Descriptive Statistics}

The first analyses were null models (no predictors at either level of analysis), which estimated the mean and the within- and between-variances. The model is below. There were $i$ days nested within $j$ persons. The variance of $\mathrm{r}_{\mathrm{ij}}$ is the within-person (level 1) variance, and the variance of $\mathrm{u}_{0 \mathrm{j}}$ is the between-person (level 2) variance.

$$
\begin{array}{cc}
\text { Within-person : } & y_{\mathrm{ij}}=\beta_{0 \mathrm{j}}+\mathrm{r}_{\mathrm{ij}} . \\
\text { Between-person : } & \beta_{0 \mathrm{j}}=\gamma_{00}+\mathrm{u}_{0 \mathrm{j}} .
\end{array}
$$


Table 1 Descriptive statistics for daily measures and the effect of the gratitude manipulation on mean daily well-being

\begin{tabular}{lccrlll}
\hline Measure & Mean & \multicolumn{2}{l}{ Variance } & Reliability & Effect for manipulation \\
\cline { 3 - 4 } & & Between & Within & \\
\hline Gratitude & 4.49 & .61 & 1.13 & .43 & $.18^{\mathrm{a}}$ \\
Self-esteem & 5.10 & .45 & 1.01 & .64 & $.16^{\mathrm{a}}$ \\
Triad & 4.93 & .37 & .81 & .79 & $.15^{\mathrm{a}}$ \\
Worry & 2.70 & .75 & 1.53 & .83 & -.07 \\
Complain & 2.33 & .44 & .81 & .40 & .01 \\
Mood PA & 4.02 & .56 & 1.45 & .70 & $.22^{*}$ \\
Mood PD & 3.86 & .51 & 1.35 & .66 & .15 \\
Mood NA & 2.90 & .64 & 1.77 & .80 & -.03 \\
Mood ND & 2.44 & .45 & 1.31 & .64 & .06 \\
Stress & 2.96 & .58 & .81 & na & -.09 \\
Number of gratitude items & 3.09 & 1.54 & 1.64 & na & \\
\hline
\end{tabular}

Coefficients accompanied by $*$ were significant at $p<.05$. Coefficients accompanied by ${ }^{\text {a }}$ were significant at $p<.10$

A summary of these analyses is presented in Table 1. One entry, "Number of gratitude items," refers only to participants in the gratitude condition. It is noteworthy that for gratitude, approximately two-thirds (65\%) of the variance was within-persons. This suggests that although feelings of gratitude can be considered as a disposition (there was meaningful between-subjects variance), it is also important to consider gratitude as a state-like construct.

To examine the impact of the gratitude manipulation on daily well-being, we included a contrast coded variable representing condition in the between person equation listed above ( $1=$ listing, $-1=$ control). The results of these analyses are also summarized in Table 1 . Similar to the results of previous studies in which gratitude has been manipulated, the effect of the gratitude manipulation on mean daily well-being was mixed. Although there were no relationships suggesting that the gratitude manipulation led to decreased well-being, there was only one significant difference between the two conditions. Individuals who described the things for which they were grateful each day reported greater positive active affect (e.g., happy). There were marginally significant effects in the same direction in the analyses of daily self-esteem and the daily measure of Beck's triad. The reductions in residual variance were $6.9 \%$ for positive active affect, and 3.4 and $3.8 \%$ respectively for self-esteem and the daily measure of Beck's triad.

\subsection{Within-Person Relationships Between Gratitude and Daily Measures}

The next set of analyses examined the within-person relationships between daily gratitude and the other daily measures we collected. The model is below. Daily gratitude was modeled as a random effect and was entered group-mean centered, which eliminated the influence of individual differences in daily stress on parameter estimates (Enders and Tofighi 2007). A summary of these analyses is presented in Table 2.

$$
\begin{array}{ll}
\text { Within-person : } & \mathrm{y}_{\mathrm{ij}}=\beta_{0 \mathrm{j}}+\beta_{1 \mathrm{j}} *(\text { Daily gratitude })+\mathrm{r}_{\mathrm{ij}} . \\
\text { Between-person : } & \beta_{0 \mathrm{j}}=\gamma_{00}+\mathrm{u}_{0 \mathrm{j}} . \\
& \beta_{1 \mathrm{j}}=\gamma_{10}+\mathrm{u}_{1 \mathrm{j}} .
\end{array}
$$


Table 2 Within-person relationships between gratitude and daily well-being
All coefficients were significant at $p<.001$

\begin{tabular}{lrrl}
\hline & Coeff. & \multicolumn{1}{l}{$t$} & Shared variance (\%) \\
\hline Self-esteem & .44 & 10.07 & 28.3 \\
Triad & .42 & 10.57 & 30.8 \\
Worry & -.36 & 6.45 & 15.2 \\
Complain & -.25 & 5.50 & 15.5 \\
Mood PA & .58 & 10.34 & 34.1 \\
Mood PD & .53 & 9.84 & 28.0 \\
Mood NA & -.44 & 7.25 & 17.3 \\
Mood ND & -.44 & 9.30 & 22.0 \\
\hline
\end{tabular}

As expected, we found that gratitude was positively related to positively valent measures of well-being (e.g., self-esteem and PA), and it was negatively related to negatively valent measures of well-being (e.g., worry and NA). On days when people felt more grateful, their well-being was higher, and on days when the felt less grateful, their wellbeing was lower. Note that because gratitude was group-mean centered, individual differences in mean daily gratitude did not contribute to these estimates.

We had no clear expectations about how these relationships might vary as a function of the gratitude manipulation. Nevertheless, we examined such differences on an exploratory basis by including a between-person level contrast variable (as described above) in the model analyzing within-person relationships between daily gratitude and daily well-being. These analyses found that the gratitude manipulation had no effect on these slopes. None of the coefficients describing this moderating variable reached or approached conventional levels of significance.

\subsection{Lagged Relationships Between Gratitude and Daily Well-Being}

To understand more thoroughly the within-person relationships between gratitude and wellbeing, we conducted a series of analyses in which we examined lagged relationships between gratitude and well-being. We conducted these lagged analyses to provide some insight into causal relationships between gratitude and well-being. Although we had no clear expectations about the causal direction these lagged analyses might indicate, much of the research on gratitude and well-being has implied or assumed that changes in gratitude lead to changes in well-being. In fact, this rationale underlies studies in which gratitude has been manipulated, under the assumption that manipulation provides a strong basis for causal inference.

In one set of analyses, well-being on day $i$ was modeled as a function of well-being and gratitude on day $i-1$. In a parallel set of analyses, gratitude on day $i$ was modeled as a function of well-being and gratitude on day $i-1$. The logic of these analyses is that temporal precedence provides a proxy for causality. If a measure on day $i-1$ predicts another measure on day $i$, this suggests that the construct assessed by the first measure is a cause of the second construct. See Nezlek (2012) and West and Hepworth (1991) for discussions of such analyses. In the models below, "WB" represents a measure of wellbeing and "Grat" represents daily gratitude. Given the requirement that there was a 1-day lag between observations, 546 days were included in these analyses. A summary of these analyses is presented in Table 3.

$$
\begin{gathered}
\mathrm{WB}(\text { day } \mathrm{i})_{\mathrm{ij}}=\beta_{0 \mathrm{j}}+\beta_{1 \mathrm{j}} *(\mathrm{WB} \text { day } \mathrm{i}-1)+\beta_{2 \mathrm{j}} *(\text { Grat day } \mathrm{i}-1)+\mathrm{r}_{\mathrm{ij}} \\
\operatorname{Grat}(\text { day } \mathrm{i})_{\mathrm{ij}}=\beta_{0 \mathrm{j}}+\beta_{1 \mathrm{j}} *(\mathrm{WB} \text { day } \mathrm{i}-1)+\beta_{2 \mathrm{j}} *(\text { Grat day } \mathrm{i}-1)+\mathrm{r}_{\mathrm{ij}} .
\end{gathered}
$$


Table 3 Lagged relationships between gratitude and daily wellbeing

\begin{tabular}{llrcc}
\hline Previous day & Present day & Coeff. & \multicolumn{1}{c}{$T$} & $p$ \\
\hline Self-esteem & Gratitude & .08 & 1.49 & .14 \\
Gratitude & Self-esteem & .00 & $<1$ & \\
Triad & Gratitude & .12 & 1.64 & .10 \\
Gratitude & Triad & -.04 & 1.01 & $\mathrm{~ns}$ \\
Worry & Gratitude & -.05 & 1.32 & $\mathrm{~ns}$ \\
Gratitude & Worry & .00 & $<1$ & \\
Complain & Gratitude & -.11 & 1.75 & .09 \\
Gratitude & Complain & .00 & $<1$ & \\
Mood PA & Gratitude & .06 & 1.08 & $\mathrm{~ns}$ \\
Gratitude & Mood PA & .03 & $<1$ & \\
Mood PD & Gratitude & .10 & 2.07 & .04 \\
Gratitude & Mood PD & .05 & $<1$ & \\
Mood NA & Gratitude & -.07 & 1.91 & .06 \\
Gratitude & Mood NA & .08 & 1.10 & $\mathrm{~ns}$ \\
Mood ND & Gratitude & -.11 & 2.41 & .02 \\
Gratitude & Mood ND & .03 & $<1$ & \\
\hline
\end{tabular}

As can be seen from the coefficients presented in Table 3, we found no support for a gratitude to well-being causal link in our data. In contrast, we found some support for a well-being to gratitude causal link. The lagged relationship in this direction was significant for positive and negative deactive affect, and it was marginally significant for negative active affect, complaining, and the measure of Beck's triad. We should note that these lagged relationships were uniformly much stronger when we analyzed daily gratitude in terms of the three items we collected, as were the zero-order slopes between well-being and gratitude. Nevertheless, given the low reliability of the three item scale, we felt that the two item measure was more valid, and so we report results using it.

We examined the moderating role of the gratitude manipulation on these significant lagged relationships, and found only one significant (or near significant) moderating effect. Experimental condition moderated the lag from negative deactive affect to gratitude $\left(\gamma_{11}=-.13, t=3.32, p<.001\right)$. Estimated values indicated that the lag from ND to gratitude was functionally 0 for the gratitude group (.01), whereas it was different from 0 for the control group $(-.12)$.

\subsection{Gratitude Manipulation as a Moderator of Within-Person Relationships between Stress and Daily Well-Being}

The next set of analyses examined the extent to which the gratitude manipulation moderated within-person relationships between stress and well-being. Daily stress was modeled as a random effect and was entered group-mean centered. As before, experimental condition was represented at level 2 with a contrast code ( -1 and 1), entered uncentered. The models for these analyses are presented below, and the results are summarized in Table 4.

$$
\begin{array}{ll}
\text { Day Level : } & \text { Well-being }=\beta_{0 \mathrm{j}}+\beta_{1 \mathrm{j}} *\left(\text { Stress }_{\mathrm{ij}}\right)+\mathrm{r}_{\mathrm{ij}} \\
\text { Person Level }: & \beta_{0 \mathrm{j}}=\gamma_{00}+\gamma_{01} *(\text { Gratitude-Condition })+\mathrm{u}_{0 \mathrm{j}} \\
& \beta_{1 \mathrm{j}}=\gamma_{10}+\gamma_{11} *(\text { Gratitude-Condition })+\mathrm{u}_{1 \mathrm{j}}
\end{array}
$$


Table 4 Relationships (slopes) between stress and well-being moderated by gratitude condition

\begin{tabular}{|c|c|c|c|c|c|c|}
\hline \multirow[t]{2}{*}{ Outcome } & \multicolumn{2}{|c|}{ Mean slope } & \multicolumn{2}{|c|}{ Moderating effect } & \multicolumn{2}{|c|}{ Estimated slopes } \\
\hline & Coeff. & t-ratio & Coeff. & t-ratio & Gratitude & Control \\
\hline Self-esteem & -.09 & $3.98 * * *$ & .02 & $<1$ & -.07 & -.11 \\
\hline Triad & -.11 & $6.20 * * *$ & .05 & $2.78 * *$ & -.06 & -.16 \\
\hline Worry & .18 & $6.06 * * *$ & -.08 & $2.58 *$ & .10 & .26 \\
\hline Complain & .27 & $7.20 * * *$ & -.03 & $<1$ & .24 & .30 \\
\hline Mood PA & -.08 & $3.12 * *$ & .07 & $2.80 * *$ & -.01 & -.15 \\
\hline Mood PD & -.14 & $5.51 * * *$ & .09 & $3.53 * *$ & -.05 & -.23 \\
\hline Mood NA & .25 & $8.55^{* * *}$ & -.07 & $2.41 *$ & .18 & .32 \\
\hline Mood ND & .12 & $5.27 * * *$ & -.04 & $1.96^{\mathrm{a}}$ & .08 & .16 \\
\hline
\end{tabular}

Coefficients accompanied by $*$ were significant at $p<.05 * *$ at $p<.01$, and $* * * p<.001$. Coefficients accompanied by ${ }^{\text {a }}$ were significant at $p<.10$

As can be seen from the coefficients presented in Table 4, on average, well-being was negatively related to stress. For positively valenced measures (e.g., self-esteem) all coefficients were negative, whereas for negatively valenced measures (e.g., worry), all coefficients were positive. These findings replicate considerable previous research on withinperson relationships between daily well-being and daily events including stress (e.g., Nezlek 2005).

As expected, these analyses found that asking participants to focus each day on the things for which they were grateful reduced their reactions to stress. Within-person relationships (slopes) between stress and daily measures of depressogenic adjustment, worry, positive-active affect (e.g., happy), positive-deactive affect (e.g., relaxed), and negativeactive affect (e.g., anxious) were weaker for participants in the gratitude condition than in the control condition (all $p \mathrm{~s}<.05$ ). Gratitude did not moderate the relationship between daily stress and self-esteem $(t<1)$ and negative deactive mood, although the $p$ value for the ND mood coefficient approached conventional levels of significance $(p=.055)$.

\section{Discussion}

For the most part, our results met our expectations. As expected, within-person relationships between gratitude and well-being were positive, and our manipulation of gratitude succeeded in reducing people's reactions to daily stress. Also as expected, our gratitude manipulation had inconsistent effects on mean well-being. Similar to previous research, listing the things for which people felt grateful each day led to greater well-being on some, but not all measures of well-being. Unexpectedly, our lagged analyses suggested that changes in well-being led to changes in feelings of gratitude more than changes in gratitude led to changes in well-being. We address these findings below.

\subsection{Within-Person Relationships Between Gratitude and Well-Being}

To our knowledge, only one study, Kashdan et al. (2006), has examined within-person relationships between well-being and gratitude. Given the sample they studied (Vietnam 
war veterans) and their measures of well-being, we thought that replicating and extending their results would be worthwhile. Our results, like theirs, showed that gratitude covaried with well-being at the within-person level in a fashion similar to the relationships that have been found at the between-person level. Moreover, we found within-person relationships between gratitude and a broad array of measures of well-being. Regardless, we believe that the results of the present study meaningfully extend our understanding of the importance of gratitude. Our results suggest that gratitude fluctuates meaningfully from day to day, and these fluctuations are associated with various aspects of well-being.

At this point, we cannot be certain exactly what mechanisms are responsible for withinperson relationships between gratitude and well-being, but the results of the lagged analyses we conducted suggest some explanations. For the most part, researchers who have studied gratitude have assumed that gratitude leads to changes in well-being. More grateful people are assumed to feel better, and this has been the rationale for studies in which gratitude has been manipulated and changes in well-being have been measured. In contrast, our analyses suggest that a lack of complaining, anxiety (NA), and depression (ND) and greater relaxation (PA) make a person feel more grateful. More relaxed people with fewer negative feelings are more grateful people.

To explore this further, we did some additional analyses in which we examined the role that stressful events might play in this. Although stressful events were negatively related to gratitude at the same-day, within-person level $(p<.001)$, there was no lag from stress to gratitude nor from gratitude to stress $(t \mathrm{~s}<1)$. Moreover, when stress and gratitude were both predictors of well-being, the coefficients for gratitude were very similar to the coefficients without stress (the values in Table 2). These analyses suggest that the lagged relationships we found did not involve stress and that the same-day relationships we found between gratitude and well-being were not mediated by stress.

Given this, we are left to consider how a lack of negative thoughts and feelings and greater feelings of relaxation might lead people to feel more grateful. At the simplest level, people may feel grateful simply if they have had a relaxing day free from negative thoughts and feelings. Nonetheless, the lack of a lagged relationship with stress is not entirely consistent with this possibility. If the simple association just described were responsible for the lagged relationships we found, one would expect to find a lag (negative) from stress to gratitude. Alternatively, relaxation and lowered negative affect may allow or predispose people to realize or to think about the things for which they are grateful. Complaining, anxiety, and depression probably do not bring to mind life's blessings, whereas relaxation and contentment may.

\subsection{The Impact of the Gratitude Manipulation}

As expected, we found that participants who listed the things for which they felt grateful each day reacted less strongly to the stressful events they experienced each day. One explanation for this might be found in Hobfoll's conservation of resources theory (Hobfoll 1989). According to this theory, individuals conserve personal resources (e.g., selfesteem), material resources (e.g., money), and social resources (e.g., social support) to be used to deal with stress, and stressful daily events consume these resources.

Within this context, recalling grateful moments may replenish resources that can then be used to adapt to or to overcome stress. Such a possibility is consistent with the fact that for the gratitude-listing group, we found that feelings of daily gratitude were positively related to the number of items people listed that day $(p=.002)$. Asking people to list the things 
for which they felt grateful was associated with stronger feelings of gratitude, which in turn resulted in more resources that could be used to deal with stress.

Our finding that our gratitude manipulation moderated relationships between stress and well-being is also consistent with research suggesting that gratitude is an important aspect of post-traumatic adjustment and growth. Gratitude was found to be an important part of personal growth that helped Vietnam War veterans deal with PTSD (Kashdan et al. 2006). Similarly, Vernon, Dillon, and Steiner (2009) found that post-trauma gratitude was negatively related to PTSD symptoms. Feeling more grateful was also related to positive functioning following the attack on the Twin Towers in the US on September 11th 2001 (Fredrickson et al. 2003; Peterson and Seligman 2003).

These findings about reactions to trauma are consistent with recent work showing that grateful thoughts result in increased physiological coherence (a measure of cardiac function) corresponding to lower stress and higher well-being (Rash et al. 2011). Rash et al. suggested that "contemplating items, moments, or events for which one is grateful may lead to greater perceived social acceptance". In turn, feeling accepted may increase selfperceived social value and may provide a new context for the interpretation of daily events.

Nevertheless, at this point, the exact mechanism that is responsible for the buffering effect of gratitude on reactions to stress is not clear. As discussed by Wood et al. (2010), gratitude interventions may have their effects through more general changes in life orientation than changes in gratitude level per se. Clearly, understanding how and why gratitude interventions such as the one we used in the present study work will require more research.

There is also the issue of the lack of significant or meaningful differences between the conditions on the measure of daily gratitude. To examine the possibility that the low reliability of the daily gratitude measure was responsible for this, we conducted an additional analysis in which we nested the two gratitude items within days and then nested days within persons. Such a three level model estimates a latent mean for each day for each person, and the resulting coefficients are adjusted for individual differences in the reliability of the measures (e.g., Nezlek 2012; pp. 98-111). The results of these analyses were virtually identical to the results of the previously reported analyses, suggesting that the low reliability of the daily gratitude measure did not contribute to the lack of a significant difference between conditions on this measure.

\subsection{Limitations and Conclusions}

No study is without limitations, and the present results need to be evaluated within the context of the limitations of the present study. First, there is the issue of the sample. Participants were adult community members, and in this regard, the present study represents an improvement over studies that have relied on university students. Nevertheless, our participants, although paid, were volunteers, and although we have no reason to believe they differed from the population at large in ways that would have influenced our results, they might have. In addition, our participants were Poles, living in and around Warsaw. Again, although we have no reason to believe that Poles differ from residents of other countries in ways that would have influenced our results, they might have. Although gratitude has been described as universal (e.g., Emmons and McCullough 2003), the dynamics of gratitude in daily life might vary cross-culturally.

Second, there is the issue of sample size and the related issue of statistical power. Estimating the power of multilevel design can be complex, (e.g., Nezlek 2011; pp. 64-65), in part because estimating the power of a MLM analysis depends upon more factors than 
estimating the power of a comparable OLS analysis (e.g., multiple regression). It is it difficult to provide an estimate that applies to all of the parameters estimated in the present study.

Nevertheless, studies by Maas and Hox (2005) and Raudenbush and Liu (2000) provide a useful estimate of the power of the present design. Maas and Hox suggest that 50 or more level 2 observations (in our case, participants) in combination with 15 level 1 observations (days in the present study) provides a reasonable basis for estimating various parameters in a MLM analysis. Raudenbush and Liu also suggest that 50 level 2 observations combined with 14 level 1 observations provide reasonable power across an array of assumptions regarding other parameters, particularly for the main effects for the gratitude manipulation. Noting all this, more observations provide more power, and a larger sample of participants that could be divided into groups, perhaps by age, might provide some insights that the present sample could not.

Finally, there are some measurement issues. First is the issue of the unreliability of the daily measure of gratitude. Although our primary hypothesis did not concern daily gratitude per se, daily gratitude figured in numerous analyses. Unreliability obscures relationships between constructs, and it may be that we would have found more lagged relationships than we did if the measure was more reliable. Second is the issue of the distinctiveness of our measures of well-being. Although there is ample evidence that some of the non-affective daily measures we collected such as self-esteem are conceptually distinct from affective measures (e.g., Nezlek 2005), such independence has not been examined within the context of gratitude. Our study was not designed to examine such independence, leaving the question unanswered for the present.

Nevertheless, we believe that the results of the present study add meaningfully to our understanding of gratitude. Our results suggest that a full understanding of gratitude needs to include within-person processes as well as between-person processes. Moreover, our lagged analyses suggest that more work needs to be done to understand the causal relationships between gratitude and various constructs, including well-being. We hope that this study and its results provide some ideas for future directions in the study of gratitude and its causes and consequences.

Acknowledgments Support for this research was provided by the Foundation for Polish Science, Bridge Grant Program: BIS/2011-3/2 to Iza Krejtz and by a grant to John B. Nezlek from the J. William Fulbright Foreign Scholarship Board, Council for International Exchange of Scholars.

Open Access This article is distributed under the terms of the Creative Commons Attribution License which permits any use, distribution, and reproduction in any medium, provided the original author(s) and the source are credited.

\section{References}

Affleck, G., Zautra, A., Tennen, H., \& Armeli, S. (1999). Multilevel daily process designs for consulting and clinical psychology: A preface for the perplexed. Journal of Consulting and Clinical Psychology, 67(5), 746-754.

Bartlett, M. Y., \& DeSteno, D. (2006). Gratitude and prosocial behavior: Helping when it costs you. Psychological Science, 17(4), 319-325.

Beck, A. T. (1972). Depression: Causes and treatment. Philadelphia: University of Pennsylvania Press.

Digdon, N., \& Koble, A. (2011). Effects of constructive worry, imagery distraction, and gratitude interventions on sleep quality: A pilot trial. Applied Psychology: Health \& Well-Being, 3(2), 193-206. doi:10.1111/j.1758-0854.2011.01049.x. 
Emmons, R. A. (2004). An introduction. In R. A. Emmons \& M. E. McCullough (Eds.), The psychology of gratitude (pp. 3-16). New York, NY: Oxford University Press.

Emmons, R. A., \& Kneezel, T. T. (2005). Giving thanks: Spiritual and religious correlates of gratitude. Journal of Psychology and Christianity, 24, 140-148.

Emmons, R. A., \& McCullough, M. E. (2003). Counting blessings versus burdens: An experimental investigation of gratitude and subjective well-being in daily life. Journal of Personality and Social Psychology, 84(2), 377-389. doi:10.1037/0022-3514.84.2.377.

Enders, C. K., \& Tofighi, D. (2007). Centering predictor variables in cross-sectional multilevel models: A new look at an old issue. Psychological Methods, 12(2), 121-138. doi:10.1037/1082-989X.12.2.121.

Feldman Barrett, L., \& Russell, J. A. (1998). Independence and bipolarity in the structure of current affect. Journal of Personality and Social Psychology, 74(4), 967-984.

Fredrickson, B. L., Tugade, M. M., Waugh, C. E., \& Larkin, G. R. (2003). What good are positive emotions in crisis? A prospective study of resilience and emotions following the terrorist attacks on the United States on September 11th, 2001. Journal of Personality and Social Psychology, 84(2), 365-376. doi:10.1037/0022-3514.84.2.365.

Froh, J., Emmons, R., Card, N., Bono, G., \& Wilson, J. (2011). Gratitude and the reduced costs of materialism in adolescents. Journal of Happiness Studies, 12(2), 289-302. doi:10.1007/s10902-0109195-9.

Geraghty, A. W. A., Wood, A. M., \& Hyland, M. E. (2010). Attrition from self-directed interventions: Investigating the relationship between psychological predictors, technique and dropout from a body image intervention. Social Science and Medicine, 71(1), 30-37. doi:10.1016/j.socscimed.2010.03.007.

Gordon, C. L., Arnette, R. A. M., \& Smith, R. E. (2011). Have you thanked your spouse today? Felt and expressed gratitude among married couples. Personality and Individual Differences, 50(3), 339-343. doi:10.1016/j.paid.2010.10.012.

Hobfoll, S. E. (1989). Conservation of resources: A new attempt at conceptualizing stress. American Psychologist, 44(3), 513-524.

Kashdan, T. B., \& Breen, W. E. (2007). Materialism and diminished well-being: Experiential avoidance as a mediating mechanism. Journal of Social and Clinical Psychology, 26(5), 521-539.

Kashdan, T. B., Uswatte, G., \& Julian, T. (2006). Gratitude and hedonic and eudaimonic wellbeing in Vietnam war veterans. Behaviour Research and Therapy, 44, 177-199. doi:10.1016/j.brat.2005.01.005.

Kerr, S. L., O’Donovan, A., \& Pepping, C. A. (2014). Can gratitude and kindness interventions enhance well-being in a clinical sample? Journal of Happiness Studies, Online, . doi:10.1007/s10902-013-94921.

Krause, N. (2006). Gratitude toward God, stress, and health in late life. Research on Aging, 28(2), $163-183$.

Kreft, I. G. G., \& de Leeuw, J. (1998). Introducing multilevel modeling. Newbury Park, CA: Sage Publications.

Kubacka, K. E., Finkenauer, C., Rusbult, C. E., \& Keijsers, L. (2011). Maintaining close relationships: Gratitude as a motivator and a detector of maintenance behavior. Personality and Social Psychology Bulletin, 37(10), 1362-1375. doi:10.1177/0146167211412196.

Lambert, N. M., Graham, S., \& Fincham, F. D. (2009). A prototype analysis of gratitude: Varieties of gratitude experiences. Personality and Social Psychology Bulletin, 35(9), 1193-1207. doi:10.1177/ 0146167209338071.

Maas, C. J. M., \& Hox, J. J. (2005). Sufficient sample sizes for multilevel modeling. Methodology, 1, 86-92.

McCullough, M. E., Emmons, R. A., \& Tsang, J. A. (2002). The grateful disposition: A conceptual and empirical topography. Journal of Personality and Social Psychology, 82(1), 112-127. doi:10.1037// 0022-3514.82.1.112.

McCullough, M. E., Tsang, J. A., \& Emmons, R. A. (2004). Gratitude in intermediate affective terrain: Links of grateful moods to individual differences and daily emotional experience. Journal of Personality and Social Psychology, 86(2), 295-309. doi:10.1037/0022-3514.86.2.295.

Meyer, T. J., Miller, M. L., Metzger, R. L., \& Borkovec, T. D. (1990). Development and validation of the Penn State Worry Questionnaire. Behaviour Research and Therapy, 28(6), 487-495.

Nezlek, J. B. (2005). Distinguishing affective and non-affective reactions to daily events. Journal of Personality, 73(6), 1539-1568. doi:10.1111/j.1467-6494.2005.00358.x.

Nezlek, J. B. (2011). Multilevel modeling for social and personality psychology. In J. B. Nezlek (Ed.) The SAGE Library in Social and Personality Psychology Methods. London: Sage Publications.

Nezlek, J. B. (2012). Diary methods for social and personality psychology. In J. B. Nezlek (Ed.), The SAGE library in social and personality psychology methods. London: Sage Publications.

Peterson, C., \& Seligman, M. E. (2003). Character strengths before and after September 11. Psychological Science, 14(4), 381-384. 
Rash, J. A., Matsuba, M. K., \& Prkachin, K. M. (2011). Gratitude and well-being: Who benefits the most from a gratitude intervention? Applied Psychology: Health and Well-Being, 3(3), 350-369. doi:10. 1111/j.1758-0854.2011.01058.x.

Raudenbush, S. W., \& Liu, X. (2000). Statistical power and optimal design for multisite randomized trials. Psychological Methods, 5, 199-213.

Roberts, R. C. (2004). The blessings of gratitude: A conceptual analysis. In R. A. Emmons \& M. E. McCullough (Eds.), The psychology of gratitude (pp. 58-78). New York: Oxford University Press.

Rosenberg, M. (1965). Society and the adolescent self-image. Princeton, NJ: Princeton University Press.

Ruini, C., \& Vescovelli, F. (2013). The Role of gratitude in breast cancer: Its relationships with posttraumatic growth, psychological well-being and distress. Journal of Happiness Studies, 14(1), 263-274. doi:10.1007/s10902-012-9330-x.

Stone, A. A., Kessler, R. C., \& Haythomthwatte, J. A. (1991). Measuring daily events and experiences: Decisions for the researcher. Journal of Personality, 59(3), 575-607. doi:10.1111/j.1467-6494.1991. tb00260.x.

Toepfer, S., Cichy, K., \& Peters, P. (2012). Letters of gratitude: Further evidence for author benefits. Journal of Happiness Studies, 13(1), 187-201. doi:10.1007/s10902-011-9257-7.

Tsang, J. A., Schulwitz, A., \& Carlisle, R. (2012). An experimental test of the relationship between religion and gratitude. Psychology of Religion and Spirituality, 4(1), 40-55. doi:10.1037/a0025632.

Vernon, L. L., Dillon, J. M., \& Steiner, A. R. W. (2009). Proactive coping, gratitude, and posttraumatic stress disorder in college women. Anxiety, Stress, \& Coping, 22(1), 117-127. doi:10.1080/ 10615800802203751.

Watkins, P. C. (2004). Gratitude and subjective well-being. In R. A. Emmons \& M. E. McCullough (Eds.), The psychology of gratitude (pp. 167-192). Oxford, UK: Oxford University Press.

Watkins, P., Scheer, J., Ovnicek, M., \& Kolts, R. (2006). The debt of gratitude: Dissociating gratitude and indebtedness. Cognition and Emotion, 20(2), 217-241. doi:10.1080/02699930500172291.

Weiner, B. (1985). An attributional theory of achievement motivation and emotion. Psychological Review, 92(4), 548-573.

West, S. G., \& Hepworth, J. T. (1991). Statistical issues in the study of temporal data: Daily experiences. Journal of Personality, 59(3), 611-662. doi:10.1111/j.1467-6494.1991.tb00261.x.

Wojciszke, B. (2005). The negative social world: The Polish culture of complaining. International Journal of Sociology, 34(4), 38-59.

Wood, A. M., Froh, J. J., \& Geraghty, A. W. A. (2010). Gratitude and well-being: A review and theoretical integration. Clinical Psychology Review, 30(7), 890-905. doi:10.1016/j.cpr.2010.03.005.

Wood, A. M., Joseph, S., Lloyd, J., \& Atkins, S. (2009a). Gratitude influences sleep through the mechanism of pre-sleep cognitions. Journal of Psychosomatic Research, 66(1), 43-48. doi:10.1016/j.jpsychores. 2008.09.002.

Wood, A. M., Joseph, S., \& Maltby, J. (2008). Gratitude uniquely predicts satisfaction with life: Incremental validity above the domains and facets of the five factor model. Personality and Individual Differences, 45(1), 49-54. doi:10.1016/j.paid.2008.02.019.

Wood, A. M., Joseph, S., \& Maltby, J. (2009b). Gratitude predicts psychological well-being above the big five facets. Personality and Individual Differences, 46(4), 443-447. doi:10.1016/j.paid.2008.11.012. 